Revista Interdisciplinaria de Humanidades, Educación, Ciencia y Tecnología

Año VII. Vol. VII. N¹. Edición Especial. 2021

Hecho el depósito de ley: pp201602FA4721

ISSN-L: 2542-3029; ISSN: 2610-802X

Universidad Nacional Experimental Francisco de Miranda (UNEFM). Santa Ana de Coro. Venezuela

Evelin Carolina Carbo-Vera; Wilson Eduardo Castro-Núñez; Ingrid Joselyne Díaz-Basurto

DOI 10.35381/cm.v7i1.534

\title{
El derecho a la prestación de alimentos en los jóvenes estudiantes en el Ecuador
}

The right to provide food for young students in Ecuador

\author{
Evelin Carolina Carbo-Vera \\ eva bonita13@hotmail.com \\ Universidad Regional Autónoma de Los Andes, Quevedo \\ Ecuador \\ https://orcid.org/0000-0002-0603-3693 \\ Wilson Eduardo Castro-Núñez \\ uq.wilsoncastro@uniandes.edu.ec \\ Universidad Regional Autónoma de Los Andes, Quevedo \\ Ecuador \\ https://orcid.org/0000-0001-8233-0510 \\ Ingrid Joselyne Díaz-Basurto \\ uq.ingriddiaz@uniandes.edu.ec \\ Universidad Regional Autónoma de Los Andes, Quevedo \\ Ecuador \\ https://orcid.org/0000-0003-2934-4010
}

Recibido: 01 de mayo de 2021

Aprobado: 01 de agosto de 2021 


\section{Estimado Editor (a):}

La norma vigente en cuanto a la aplicación del número 2, del Artículo. 4 del Libro II, Título V, del Código Orgánico de la Niñez y Adolescencia de Ecuador del 2020, faculta a los progenitores a solicitar al Juez de las Unidades Judiciales de la Familia, Mujer, Niñez y Adolescencia la Prescripción del Derecho a prestar alimentos a sus hijas e hijos que hayan cumplido 21 años de edad, y se encuentren cursando sus estudios, esta situación afecta gravemente la culminación de la carrera universitaria, pues en muchos casos la prestación de alimentos que realizan los padres, constituye el único sustento económico con que cuentan las y/o estudiantes, y la falta de ese recurso podría obligarlos a abandonar su superación, lo ideal sería que este beneficio no sea interrumpido con la prescripción a los 21 años, sino que se asegure su continuidad hasta que el beneficiario haya concluido al menos su formación de tercer nivel. Al respecto, Urgilés Amoroso, Erazo Álvarez, Narváez Zurita y Vázquez Calle (2020), plantean que:

Las pensiones alimenticias son un tema que produce gran debate en los estudios constitucionales, debido a su amplitud. Uno de los temas que se estudia de forma constante es la responsabilidad del alimentante y las condiciones que este debería tener para asumir dicha responsabilidad. (p.289)

En la actualidad existen cientos de miles de jóvenes que años tras años hacen trámites de ingreso a una universidad pública y no lo logran, el término rechazado es el que los identifica. El sistema educativo nacional los rechaza de ingresar a una universidad pública, orillándolos a optar por una universidad privada y enfrentarse al inalcanzable reto de costear sus estudios, pues las instituciones privadas son costosas y no accesibles para la mayoría, es allí donde se evidencia la necesidad por parte de los jóvenes estudiantes de percibir una pensión alimenticia que contribuya a solventar sus gastos académicos. Este hecho se complica con la situación social y económica de las y los jóvenes que han cumplido 21 años de edad y se encuentran cursando los últimos años de su carrera universitaria, siendo estos beneficiarios de prestaciones alimenticias por parte de uno de sus progenitores, quienes habiendo estado a la 
espera de que su hija y/o hijo llegaran a esa edad, pretenden solicitar y han solicitado al juez la extinción de la obligación.

En este sentido, se despresen una relación entre la familia y las normas vigente al repecto Saldaña Erraez, M., Quezada Soto, M., y Durán Ocampo, A. (2020) lo manifiestan de la siguiente forma:

Para comprender cómo se relacionan el Derecho de Familia y el Derecho Civil se precisa colocar este último como una rama del derecho privado que se encarga de regular, entre otros aspectos, las relaciones familiares, 0 , dicho de otro modo, ubicar el Derecho de Familia como aquella rama del Derecho Civil que regula las relaciones personales y patrimoniales de la familia, tales como las matrimoniales, las que se desarrollan entre padres e hijos, así como los diversos derechos como el de la alimentación, la protección, las herencias y otros que conforman la sucesión familiar. (p.262)

Por mandato legal la prestación alimenticia a los jóvenes, suele terminar a los 18 años de edad siempre y cuando, este no se encuentre cursando estudios a cualquier nivel académico, esta obligación puede extenderse hasta los 21 años de edad, siempre y cuando, como se indicó antes, el joven se encuentre cursando estudios. Sin embargo, entendiendo que la disposición legal referida debe cambiar, en el sentido de que permita la continuidad del derecho a alimentos a pesar de haber cumplido la mencionada edad y de esta manera se obligue a la o el progenitor que esté prestando el derecho de alimentos, a que lo haga hasta que su hija o hijo termine sus estudios. Para establecer los parámetros legales y análisis la norma vigente se muestra el siguiente cuadro. 


\section{Cuadro 1.}

Normativa Legal.

\begin{tabular}{|c|c|}
\hline Normativa Legal & Artículos \\
\hline $\begin{array}{l}\text { Constitución de la República del Ecuador } \\
\text { (2008) }\end{array}$ & $\begin{array}{l}\text { Artículo } 45 \text {.- Las niñas, niños y adolescentes } \\
\text { gozarán de los derechos comunes del ser } \\
\text { humano, además de los específicos de su } \\
\text { edad. El Estado reconocerá y garantizará la } \\
\text { vida, incluido el cuidado y protección desde } \\
\text { la concepción. } \\
\text { Las niñas, niños y adolescentes tienen } \\
\text { derecho a la integridad física y psíquica; a su } \\
\text { identidad, nombre y ciudadanía; a la salud } \\
\text { integral y nutrición; a la educación y cultura, } \\
\text { al deporte y recreación; a la seguridad social; } \\
\text { a tener una familia y disfrutar de la } \\
\text { convivencia familiar y comunitaria; a la la } \\
\text { participación social; al respeto de su libertad } \\
\text { y dignidad; a ser consultados en los asuntos } \\
\text { que les afecten; a educarse de manera } \\
\text { prioritaria en su idioma y en los contextos } \\
\text { culturales propios de sus pueblos y } \\
\text { nacionalidades; y a recibir información } \\
\text { acerca de sus progenitores o familiares } \\
\text { ausentes, salvo que fuera perjudicial para su } \\
\text { bienestar. } \\
\text { Art. 328.- La remuneración será justa, con un } \\
\text { salario digno que cubra al menos las } \\
\text { necesidades básicas de la persona } \\
\text { trabajadora, así como las de su familia; será } \\
\text { inembargable, salvo para el pago de } \\
\text { pensiones por alimentos. }\end{array}$ \\
\hline $\begin{array}{l}\text { Código de la Niñez y Adolescencia } \\
\text { (2003) }\end{array}$ & $\begin{array}{l}\text { Artículo 4.-Titulares del derecho de } \\
\text { alimentos. - (Agregado por el Art. Único de la } \\
\text { Ley s/n, R.O. } 643 S, 28 \mathrm{~V} I \mathrm{II} 2009 \text { ). } \\
\text { Tienen derecho a reclamar alimentos: } \\
\text { 1. Las niñas, niños y adolescentes, salvo los } \\
\text { emancipados voluntariamente que tengan } \\
\text { ingresos propios, a quienes se les } \\
\text { suspenderá el ejercicio de éste derecho de } \\
\text { conformidad con la presente } \\
\text { norma; } \\
\text { 2. Los adultos o adultas hasta la edad de } 21 \\
\text { años que demuestren que se encuentran } \\
\text { cursando estudios en cualquier nivel } \\
\text { educativo que les impida o dificulte } \\
\text { dedicarse a una actividad productiva y }\end{array}$ \\
\hline
\end{tabular}




\begin{tabular}{|c|c|}
\hline & $\begin{array}{l}\text { carezcan de recursos propios y suficientes; } \\
\text { y, } \\
\text { 3. Las personas de cualquier edad, que } \\
\text { padezcan de una discapacidad o sus } \\
\text { circunstancias físicas o mentales les impida } \\
\text { o dificulte procurarse los medios para } \\
\text { subsistir por sí mismas, conforme } \\
\text { conste del respectivo certificado emitido por } \\
\text { el Consejo Nacional de Discapacidades } \\
\text { CONADIS, o de la institución de salud que } \\
\text { hubiere conocido del caso que para el efecto } \\
\text { deberá presentarse. } \\
\text { Capítulo II } \\
\text { DEL PROCEDIMIENTO PARA LA } \\
\text { FIJACIÓN Y COBRO DE PENSIONES } \\
\text { ALIMENTICIAS Y DE SUPERVIVENCIA }\end{array}$ \\
\hline Código Civil (2015) & $\begin{array}{l}\text { Art. 1002.- Los alimentos que el causante ha } \\
\text { debido por ley a ciertas personas, no gravan } \\
\text { la masa hereditaria, sino sólo al partícipe de } \\
\text { la sucesión a quien el testador haya } \\
\text { impuesto esa obligación. } \\
\text { Los alimentarios no descendientes ni } \\
\text { ascendientes que gocen de pensión en vida } \\
\text { del causante, tendrán acción contra los } \\
\text { herederos, a prorrata de la cuota hereditaria. } \\
\text { La pensión alimenticia podrá disminuir o } \\
\text { extinguirse, con arreglo a las reglas } \\
\text { generales, pero no podrá ser aumentada. } \\
\text { Art. } 2388 .- \text { No se reconocen otras causas de } \\
\text { preferencia que las indicadas en la ley. } \\
\text { Con relación a los créditos públicos no hay } \\
\text { más derechos preferentes que la hipoteca, la } \\
\text { prenda, la pensión alimenticia y lo que se } \\
\text { deba a los trabajadores por concepto de } \\
\text { salarios, sueldos, indemnizaciones y } \\
\text { pensiones jubilares. }\end{array}$ \\
\hline
\end{tabular}

Elaboración: Los autores. 
Además, es importante señalar lo planteado por Arroyo (2020), en relación a las violaciones del derecho en cuanto a la pensión y su extensión a la vulneración de otros:

El no pago de las pensiones ciertamente representa una violación a los derechos de la niñez, pero constituye también una forma de violencia contra las mujeres, la violencia patrimonial, y el reforzamiento de las masculinidades hegemónicas. Esta forma de violencia ha sido naturalizada por la sociedad pues se acepta sin cuestionamientos que son las mujeres las que cuidan a su prole. (p.130)

Es importante mencionar la gran responsabilidad que tienen los padres para con sus hijos al cubrir todas las necesidades básicas para su máximo bienestar e interés superior, y como padres ayudar a sus hijos aun cuando ya son independientes, las y los jóvenes que estudian esto es una ayuda innegable y les va a generar un alivio el contar con un apoyo económico, esto le permitirá inclusive concentrarse más en sus estudios, esto es un punto a favor pues hay casos de personas que tienen que escoger entre estudiar y trabajar y desertan de sus estudios.

\section{FINANCIAMIENTO}

No monetario.

\section{AGRADECIMIENTO}

A la Universidad Regional Autónoma de los Andes, Quevedo, Ecuador por motivar el desarrollo de la Investigación.

\section{REFERENCIAS}

Arroyo, R. (2020). La Economía de Género: Las Pensiones Alimenticias y su Relación con la Paternidad y los Derechos Humanos de las Mujeres. Revista latinoamericana de educación inclusiva, 14(2), 131-150. https://dx.doi.org/10.4067/s0718-73782020000200131 
Asamblea Nacional Constituyente de la República del Ecuador, (2008). Constitución de la República del Ecuador. Montecristi. Registro Oficial 449 de 20-oct-2008. Recuperado de https://n9.cl/sia

Congreso Nacional (2015). Código Civil. Registro Oficial 506 de 22 de mayo de 2015. Codificación No. 2005010. Recuperado de: https://n9.cl/02pjho

Congreso Nacional. (2003). Código de la niñez y adolescencia. [ Childhood and Adolescence Code]. Quito. Recuperado de: https://n9.cl/fokqg

Saldaña Erraez, M., Quezada Soto, M., y Durán Ocampo, A. (2020). La enseñanza del derecho de familia en su relación con el derecho civil. Revista Universidad y Sociedad, 12(3), 260-266. Recuperado de: https://n9.cl/5tibz

Urgilés Amoroso, M.; Erazo Álvarez, J.; Narváez Zurita, C.; Vázquez Calle, J. (2020). La exención del pago de pensiones alimenticias a partir de la interpretación de la Constitucional. Iustitia Socialis, 5(9),287-313. http://dx.doi.org/10.35381/racji.v5i9.761 